\title{
Cyclosporiasis Among School Going Children of Kathmandu Valley
}

\author{
Shardulendra Prasad Sherchand ${ }^{1}$, Dev Raj Joshi ${ }^{2}$, Nabaraj Adhikari ${ }^{3}$, Krishna Prasad Pant ${ }^{4}$ \\ and Ramesh Pun ${ }^{5}$ \\ ${ }^{1}$ National College, Khusibu, Kathmandu, ${ }^{2}$ Central Department of Microbiology, Kirtipur \\ Kathmandu, ${ }^{3}$ Kantipur College of Medical Sciences, Sitapaila, Kathmandu, ${ }^{4}$ Siddhanath \\ Science Campus, Mahendranagar, Kanchanpur and ${ }^{5}$ Nepal Academy of Science and \\ Technology, Khumaltar Lalitpur \\ e-mail:Shardulendras@gmail.com
}

\begin{abstract}
Intestinal parasitic infections among children possess a critical public health issue in Nepal. This study was conducted to determine cyclosporiasis among school going children of Kathmandu valley. A total of 187 collected stool samples were subjected to direct microscopy, formal-ether concentration technique, Sheather's sucrose floatation technique and modified acid fast staining technique. The incidence of cyclosporiasis, cryptosporidiosis and other intestinal parasitosis was $24.1 \%, 29.4 \%$ and $51.9 \%$ respectively. The cyclosporiasis was higher in female (28.4\%) without any significance $(\mathrm{p}=0.190)$. The cyclosporiasis was found highest in age group 5-8 (25.2\%) but statistically insignificant $(\mathrm{p}=0.895)$. Cyclosporiasis was higher in symptomatic case $(25.6 \%)$ but found statistically insignificant $(\mathrm{p}=0.469)$. Similarly, cyclosporiasis was higher in school children without following hygienic practice $(28.0 \%)$ but without any significance $(\mathrm{p}=0.103)$. There was significant difference between detection of cyclospora before and after sporulation by modified acid fast staining technique $(\mathrm{p}<0.001)$ and highest association was seen between Cyclospora cayetanensis and Cryptosporidium parvum. The outcome of this study revealed that cyclosporiasis remain highly endemic in school children of Kathmandu valley. This suggests proper diagnosis and specific treatment is required to lower the parasitic burden.
\end{abstract}

Key words: Cyclospora cayetanensis, Cryptosporidium parvum, modified acid fast staining technique

\section{Introduction}

The cyclosporiasis is an emerging disease found in both immunocompromised and immunocompetent person. C. cayetanensis is specific to humans (Ortega et al. 1993) and its infection leads to watery diarrhea with the absence of any leucocytes or blood (Powell 1995). The carriers may be temporary in immunocompetent hosts or chronic in immunocompromised hosts (Eberhard et al. 2000). Cyclosporiasis is found in patients from 12- 87 year old age. Indirect transmission through flies, fingers, fomites and food is the usual mode of transmission. Epidemiologic data indicate that the human-associated cyclospora is transmitted by water and food (Hoge et al. 1995). Sexual and racial predilection does not appear to exist for cyclosporiasis. The low socio-economic groups of people are more susceptible to cyclospora than the people of high socio-economic groups. People with the occupation of sex work, farming, kitchen activities, hospital works, and school children are the vulnerable groups for cyclosporiasis (Ghimire et al. 2005). Current information on the epidemiology of cyclosporiasis comes from Nepal, Haiti and Peru (John \& Petri 2006).

Immunity may not occur after infection however, some amount of immunity may be present in adults who are exposed to the infection as the infection is less prevalent in adults living in endemic areas. High oocysts frequency case has been observed in the stool of diarrheal persons and AIDS patients (Sherchand \& Cross 2003). The unsporulated oocysts require some days for sporulation outside the human beings, however, the environment may trigger the development process in the oocysts (Smith et al. 1997). The present 
study has been designed to analyze present situation of cyclosporiasis among school going children in Kathmandu valley and its relation with behavioral pattern and life style of the children relating to health.

\section{Methodology}

A total of 187 stool samples were collected from school going children of Kathmandu valley in a screw capped plastic container. A questionnaire consisting age, sex, hygienic practices and gastrointestinal symptoms were filled. All the samples were processed in Microbiology Laboratory of National College, Kathmandu. Each fresh stool sample was examined macroscopically and microscopically for the detection of parasites. Microscopic examination of samples was done by standard formal-ether concentration method. Sheather's sucrose floatation method followed by modified acid fast staining was conducted for detecting oocysts of Cryptosporidium spp. and Cyclospora spp. Cyclospora positive specimens were stored at ambient temperature in $2.5 \%$ potassium dichromate for about 10 days and were examined for sporulation. The data obtained were analyzed by statistical software SPSS (version 11.5).

\section{Results}

Among 187 stool samples, the prevalence of cyclosporiasis was $24.1 \%$. The genderwise distribution of cyclosporiasis in school going children revealed that the prevalence was higher among females (28.4\%) than males (20.2\%) (Table 1). However, the genderwise occurrence of cyclosporiasis was found statistically insignificant. The prevalence of cyclosporiasis was found highest in the age group 5-8 (25.2\%) (Table 2). The occurrence of cyclosporiasis in different age group was statistically insignificant. The occurrence of $C$. cayetanensis in symptomatic case (25.6\%) was higher than asymptomatic case (20.7\%) but it was found statistically insignificant (Table 3). The occurrence of $C$. cayetanensis in school going children without maintaing hygienic practice (28.0\%) was higher than with maintaining hygienic practice (17.4\%) but, the result was found statistically insignificant (Table 4). There was high significant difference between detection of cyclospora before and after sporulation by modified acid fast staining technique (Table 5). Highest association was between C. cayetanensis and Cryptosporidium parvum (67.3\%) (Table 6).
Table 1. Genderwise distribution of $C$. cayetanensis

\begin{tabular}{l|c|l|l|l}
\hline Sex & Frequency (n) & Positive(n) & $\mathbf{\%}$ & p value \\
\hline Male & 99 & 20 & 20.2 & $\mathrm{p}=0.190$ \\
Female & 88 & 25 & 28.4 & \\
Total & $\mathbf{1 8 7}$ & $\mathbf{4 5}$ & $\mathbf{2 4 . 1}$ & \\
\hline
\end{tabular}

Table 2. Frequency distribution of $C$. cayetanensis with age

\begin{tabular}{l|l|c|l|l}
\hline Age & $\begin{array}{c}\text { Frequency } \\
\text { (n) }\end{array}$ & $\begin{array}{c}\text { Positive } \\
\text { (n) }\end{array}$ & $\mathbf{\%}$ & p value \\
\hline 3-5 years & 46 & 10 & 21.7 & $\mathrm{p}=0.895$ \\
5-8 years & 107 & 27 & 25.2 & \\
8-12 years & 34 & 8 & 23.5 & \\
Total & $\mathbf{1 8 7}$ & $\mathbf{4 5}$ & $\mathbf{2 4 . 1}$ & \\
\hline
\end{tabular}

Table 3. Symptom wise distribution of C. cayetanensis

\begin{tabular}{l|l|l|l|l}
\hline Symptoms & $\begin{array}{l}\text { Frequency } \\
\text { (n) }\end{array}$ & $\begin{array}{l}\text { Positive } \\
\text { (n) }\end{array}$ & \% & p value \\
\hline Symptomatic & 129 & 33 & 25.6 & $\mathrm{p}=0.469$ \\
Asymptomatic & 58 & 12 & 20.7 & \\
Total & $\mathbf{1 8 7}$ & $\mathbf{4 5}$ & $\mathbf{2 4 . 1}$ & \\
\hline
\end{tabular}

Table 4. Distribution of $C$. cayetanensis with hygiene practice

\begin{tabular}{l|c|c|c|c}
\hline $\begin{array}{l}\text { Hygien e } \\
\text { Practice }\end{array}$ & $\begin{array}{l}\text { Frequency } \\
\text { (n) }\end{array}$ & $\begin{array}{l}\text { Positive } \\
\text { (n) }\end{array}$ & \% & p value \\
\hline Following & 69 & 12 & 17.4 & $\mathrm{p}=0.103$ \\
Not Following & 118 & 33 & 28.0 & \\
Total & $\mathbf{1 8 7}$ & $\mathbf{4 5}$ & $\mathbf{2 4 . 1}$ & \\
\hline
\end{tabular}

Table 5. Comparison of C. cayetanensis detected from different techniques

\begin{tabular}{l|lc|l|l}
\hline $\begin{array}{l}\text { Modified acid } \\
\text { fast staining } \\
\text { after sporulat- } \\
\begin{array}{l}\text { ion in 2.5\% pota- } \\
\text { ssium dichromate }\end{array}\end{array}$ & $\begin{array}{l}\text { First modified acid } \\
\text { fast staining } \\
\text { before sporulation }\end{array}$ & Total & p value \\
\hline $\begin{array}{l}\text { Positive (n) } \\
\text { Negative (n) }\end{array}$ & 11 & 19 & 30 & $\mathrm{p}<0.001$ \\
Total & $\mathbf{2 5}$ & $\mathbf{1 6 2}$ & $\mathbf{1 8 7}$ & \\
\hline
\end{tabular}


Table 6. Association of $C$. cayetanensis with other intestinal parasites

\begin{tabular}{l|l|l}
\hline Parasites detected & Cyclospora cayetanensis (n) & \% \\
\hline Cryptosporidium parvum & 41 & 67.3 \\
Giardia lamblia & 9 & 14.7 \\
Entamoeba histolytica & 8 & 13.2 \\
Entamoeba hartmani & 1 & 1.6 \\
Ascaris lumbricoides & 1 & 1.6 \\
Trichuris trichiura & 1 & 1.6 \\
Entamoeba coli & 0 & 0 \\
Strongyloides stercoralis & 0 & 0 \\
Total & $\mathbf{6 1}$ & $\mathbf{1 0 0}$
\end{tabular}

\section{Discussion}

The occurrence of cyclosporiasis was $24.1 \%$. This finding was higher than the findings of Kimura et al. (2005) and Ghimire et al. (2005). The finding was similar to the finding of Sherchand et al. (1999) where prevalence of cyclosporiasis was $29.8 \%$.

In endemic countries like Nepal, the annual attack rate for $C$. cayetanensis has been reported to be as high as 40\% (Sherchand et al. 1999). These differences may be due to different geographical areas, seasons, time, climatic condition, socioeconomic factors of the population, non-specific treatment, lack of proper diagnosis, etc. (Adam et al. 2000). This high prevalence can also be correlated with the epidemiological routes of food borne and water borne transmission of intestinal parasites. In rainy season, the seepage of water from the distribution pipe or rain water may contaminate vegetables either when they are openly kept on the ground for sale or in the fields just before harvesting. Similarly, the use of human waste as fertilizer for plants or indirectly via contaminated sewage water used for crop irrigation and during washing of products might be other reasons for high prevalence of cyclosporiasis (Ghimire et al. 2008).

The genderwise distribution of cyclosporiasis in school going children revealed higher prevalence in female school going children (28.4\%) than in male school going children (20.2\%) but the result was statistically insignificant $(\mathrm{p}=0.190)$. But the higher prevalence in females can be correlated with their working habit in kitchen, consumption of different raw items such as panipuri, Chana Chatpatae, fruits and vegetables which may be contaminated with oocysts of $C$. cayetanensis. Other factors for higher prevalence of cyclosporiasis with females can be due to less active immune system of females followed by the loss of antibody through bleeding/menstruation and parturition. But, all the children were below 12 years so this may not be the reason in our case (Ghimire et al. 2008). Literature has shown that there is no sexual predilection (Chacin-Boralla et al. 2001). This insignificant result has clearly given significant message that there is no discrimination between sex of the person and chances of being infected by the parasites.

In the present study, the prevalence of cyclosporiasis was found highest in age group 5-8 (25.2\%) but it was statistically insignificant ( $\mathrm{p}=0.895)$. In contrary to our research, the research conducted by Charles (1995) showed that higher prevalence of cyclosporiasis in age less than 18 months. But, our result was similar to the result conducted by Kimura et al. (2005). Many researchers throughout the world have also suggested that the children and elderly people are more vulnerable towards cyclosporiasis. This might be due to the low immunity power of these groups. Besides, young children play here and there, they don't bother much about hygienic practice, eat and drink whatever they get, so, their chances of acquiring parasitic infestation is very high. The current finding was similar to Sherchand and Sharma (2003) where cyclosporiasis was found highest in the age group 25-60 months (12\%).

The occurrence of $C$. cayetanensis in symptomatic case $(25.6 \%)$ was higher than asymptomatic case (20.7\%) but it was found statistically insignificant $(p=0.469)$. The occurrence of $C$. cayetanensis in school going children without maintaining hygienic practice (28.0\%) was higher than with maintaining hygienic practice (17.4\%) but the result was found statistically insignificant ( $\mathrm{p}=0.103)$. The person maintaining good 
hygiene is less vulnerable to the parasitic infestation than those not maintaining hygienic practice. But, current insignificant result might be due to the limitation of questionnaire.

The oocysts of $C$. cayetanensis must undergo sporulation as unsporulated oocysts are not infective to man. So the clean environment will certainly provide unfavorable condition for the sporulation of oocysts and there is less chance of being infected with it. This is due to the influx of people in the valley, unplanned housing, poor sewage systems, street flooding and environmental contamination with fecal matter. Chlorination is virtually ineffective in municipal water supply of Kathmandu due to the high level of contamination with organic matter. Oocysts of $C$. cayetanensis is resistant to chlorination compared with diarrheagenic bacteria, and can be present even in coliform free water. Therefore, it appears that water and vegetables plays a major role in transmitting $C$. cayetanensis infection in Nepal (Adhikari et al. 2006). Oocysts of $C$. cayetanensis have also been detected in sewage water, vegetables, and feces of animals and birds which may be an additional source of environmental contamination (Sherchand et al. 1999). But, the result of present study does not show any sort of relationship between cyclosporiasis and good hygiene practice, which may be due to small sample size, biasness during questionnaire filling, shyness of school going children, lack of proper knowledge etc. There was significant difference between detection of cyclospora before and after sporulation by modified acid fast staining technique $(\mathrm{p}<0.001)$. Highest association was between $C$. cayetanensis and Cryptosporidium parvum (67.3\%). This result clearly demonstrates the high prevalence of $C$. cayetanensis.

Thus, cyclosporiasis is one of the most prevalent intestinal protozoal parasite. Effective control strategies as well as knowledge and proper hygienic education are necessary to combat the parasitic infection of this parasite.

\section{Acknowledgements}

The authors extend their sincere gratitude to school going children of Ganesh Himal Secondary School, Samakhusi, Kathmandu, Kopila English Secondary School, Siddhipur, Lalitpur and Samata Shikshya Niketan, Kamalvinayak, Bhaktapur for providing stool samples and National College for providing the laboratory facilities.

\section{References}

Adam, R.D., Y.R. Ortega, R.H. Gilman and S. Charles. 2000. Intervening transcribed spacer region 1 variability in Cyclospora cayetanensis. American Society for Clinical Microbiology 38(6):2339-2343.

Adhikari, N., S.K. Rai and A. Singh. 2006. Intestinal parasitic infections among HIV seropositive and high risk group subjects for HIV infection in Nepal. Nepal Medical College Journal 9:166-170.

Chacin-Bonilla, L., J. Estevez, F. Monsalve and L. Quijada. 2001. Cyclospora cayetanensis infections among diarrhoel patients from Venezuela. American Journal of Tropical Medicine and Hygiene 65:351-354.

Charles, W. 1995. Prevalence of Cyclospora species and other enteric pathogens among children less than 5 years of age. Nepal Journal of Clinical Microbiology 3058-3060.

Eberhard, M.L., Y.R. Ortega, D.E. Hanes, E.K. Nace, R.Q. Do and M.G. Robl, K.Y. Won, C. Gavidia, N.L. Sass, K. Mansfield, A. Gozalo, J. Griffiths, R. Gilman, C.R. Sterling and M.J. Arrowood. 2000. Attempts to establish experimental Cyclospora cayetanensis infection in laboratory animals. Journal of Parasitology 86:577-582.

Ghimire, T.R., P.N. Mishra and J.B. Sherchand. 2008. Epidemiology of Cyclospora cayetanensis in HIV/ AIDS patient in Kathmandu, Nepal. Journal of Nepal Health Research Council 6(12):28-37.

Ghimire, T.R., P.N. Mishra and J.B. Sherchand. 2005. The seasonal outbreaks of cyclospora and cryptosporidium in Kathmandu, Nepal. Journal of Nepal Health Research Council 3(1):39-48.

Hoge, C.W., P. Echeverria, R. Rajah. J. Jacobs, S. Malthouse, E. Chapman, L.M. Jimenez and D.R. Shlim. 1995. Prevalence of Cyclospora species and other enteric pathogens among children less than 5 years of age in Nepal. Journal of Clinical Microbiology 33(11):3058-3060.

John, D.T. and W.A. Petri. 2006. Markell and Voge's Medical Parasitology. $9^{\text {th }}$ edition. Saunders Elsevier. Pp. 23-78.

Kimura, K., S.K. Rai, G. Rai and S. Uga. 2005. Study on Cyclospora cayetanensis associated with diarrheal disease in Nepal and Loa PDR. Southeast Asian Journal of Tropical Medicine and Public Health 36:1371-1376.

Ortega, Y.R., C.R. Sterling, R.H. Gilman, V. Cama and F. Diaz. 1993. Cyclospora species: a new protozoan pathogen of humans. New England Journal Medicine 328: 1308-1312.

Powell, D. 1995. Approach to the patient with diarrhea. In: Textbook of gastroenterology, 2nd ed. T. Yamada. JB Lippincott, Pp. 820-824. 
Shardulendra Prasad Sherchand et al./Cyclosporiasis Among.....

Sherchand, J.B. and J.H. Cross. 2003. Cyclospora cayetanensis in Nepal: A study of epidemiological and microbial aspects. Journal of Nepal Health Research Council 3:1-8.

Sherchand, J.B. and D.R. Sharma. 2003. A study of Cyclospora cayetanensis and the possible contamination of vegetables and river water in Kathmandu, Nepal. Journal of Nepal Association of Medical Laboratory Science 5:13-17.
Sherchand, J.B., J.H. Cross and M. Jimba. 1999. Study of Cyclospora cayetanensis in health care facilities, sewage water and green leafy vegetables in Nepal. Southeast Asian Journal of Tropical Medicine Public Health 30(1):58-63.

Smith, H.V., C.A. Paton, M.M.A. Mtambo and R.W.A. Girdwood. 1997. Sporulation of Cyclospora species oocysts. Applied Environmental Microbiology 63:1631-1632. 
Nepal Journal of Science and Technology 11 (2010) 193-198 